\title{
Biochemical Population Genetics of Redfishes (Sebastes) off Newfoundland
}

\author{
R. H. Payne \\ Division of Basic Sciences, Faculty of Medicine \\ Memorial University of Newfoundland \\ St. John's, Newfoundland, Canada A1B 3V6 \\ and \\ I-Hsun $\mathrm{Ni}$ \\ Department of Fisheries and Oceans, Fisheries Research Branch \\ Northwest Atlantic Fisheries Centre, P. O. Box 5667 \\ St. John's, Newfoundland, Canada A1C 5X1
}

\begin{abstract}
Electrophoretic analysis of liver enzyme variants from redfish specimens, classified as Sebastes marinus and Sebastes fasciatus on the basis of meristics and gasbladder musculature, provides clear evidence that these taxa are valid biological species. It is also evident that $S$. fasciatus and $S$. mentella are genetically distinct and that $S$. mentella is more closely related to $S$. marinus than to $S$. fasciatus. These preliminary analyses indicate that it may soon be possible to devise a biochemical genetic protocol that will readily and accurately distinguish specimens of the three sibling redfish species in the Northwest Atlantic.
\end{abstract}

\section{Introduction}

The taxonomic status of redfishes in the Northwest Atlantic has been controversial for many years. Templeman and Sandeman (1957) pointed out two distinct "types" of redfish in the region which may correspond to the European species, Sebastes mentella Travin and Sebastes marinus (Linnaeus). Specimens classified as the "mentella-type" or "beaked" redfish are bright red in color with a well-developed bony protrusion on the lower jaw and a large eye, whereas those classified as "marinus-type" or "golden" redfish are orange to orange-red in color with a poorly-developed protrusion on the lower jaw and a relatively small eye. Specimens with intermediate characteristics are quite common. The situation has become further complicated by the work of Barsukov (1968) who recognized two species of beaked redfishes off eastern North America: S. mentella Travin and S. fasciatus Storer. Although morphological differences among the redfishes were described by Barsukov (1972), Barsukov and Zakharov (1972), Litvinenko (1974, 1980), Templeman (1980) and $\mathrm{Ni}$ (1981a, 1981b), opinions are still expressed that the morphological differences are merely geographic variations within the same species rather than among species (NAFO, 1981).

The rapid increase in the commercial utilization of Northwest Atlantic redfishes in recent decades and the consequent need to develop an effective conservation policy for the resource has caused attention to be focused on the biology of redfishes. It is, of course, axiomatic that little progress in biological understanding can be made until the taxonomic problems have been resolved. This paper attempts to contribute to the solution by providing the results of an analysis of biochemical variation among redfishes in samples taken off Newfoundland.

\section{Materials and Methods}

The redfish samples, consisting of $63 \mathrm{~S}$. fasciatus, 39 S. marinus and $5 S$. mentella, were collected during an otter-trawl survey off southern Newfoundland (St. Pierre Bank) by the research vessel $A$. T. Cameron in June 1981. The specimens were caught in depths from 147 to $472 \mathrm{~m}$, where bottom temperatures ranged from $2.1^{\circ}$ to $5.8^{\circ} \mathrm{C}$. In addition, 31 specimens of $S$. mentella were obtained from a catch of the commercial trawler Cape Fox fishing off southern Labrador (Hamilton Bank) at 307-314 m on 20 September 1982. Classification of the specimens into species, based on extrinsic gasbladder musculature as described by $\mathrm{Ni}$ (1981a) and Power and $\mathrm{Ni}$ (1982), was carried out independently prior to the biochemical genetic analysis. Heart, liver and skeletal muscle samples were dissected from each specimen and individually frozen. The carcasses were then preserved in 10\% formalin for future checking of the gasbladder musculature, if necessary. Prior to dissection and preservation, the specimens were measured as fork length to the nearest centimeter. The length ranges of the specimens were $23-58 \mathrm{~cm}$ for $S$. marinus, $13-42 \mathrm{~cm}$ for $S$. fasciatus and $26-41 \mathrm{~cm}$ for $S$. mentella. 
The following abbreviations for various biochemical terms terms have been used throughout the text:

\begin{tabular}{|c|c|}
\hline IDH & - isocitrate dehydrogenase \\
\hline $\mathrm{LDH}$ & - lactate dehydrogenase \\
\hline $\mathrm{MDH}$ & - malate dehydrogenase \\
\hline MTT & $\begin{array}{c}\text { - 3-(4,5-dimethylthiazolyl-2)-2,5-di- } \\
\text { phenyltetrazolium bromide }\end{array}$ \\
\hline NAD & - nicotinamide adenine dinucleotide \\
\hline NADP & $\begin{array}{l}\text { - nicotinamide adenine dinucleotide } \\
\text { phosphate }\end{array}$ \\
\hline & -6-phosphogluconate dehydrogenase \\
\hline PGI & - phosphoglucose isomerase \\
\hline PGM & - phosphoglucomutase \\
\hline PMS & - phenazine methosulphate \\
\hline SOD & - superoxide dismutase \\
\hline 'tris' & $\begin{array}{l}\text {-2-amino-(hydroxymethyl)propane-1, } \\
\text { 3-diol }\end{array}$ \\
\hline
\end{tabular}

In the laboratory, liver specimens were homogenized with an equal volume of $30 \%$ dimethyl sulphoxide, $70 \mathrm{mM}$ 'tris', $\mathrm{pH} 7.5$, and the homogenates were centrifuged at $4,000 \times \mathrm{G}$ for $15 \mathrm{~min}$. The buffer system for starch gel electrophoresis was $135 \mathrm{mM}$ 'tris', $45 \mathrm{mM}$ citric acid, $\mathrm{pH} 7.0$, which was used full strength in the electrode vessels and diluted 1 to 15 for gel preparation (Ayala et al., 1972). Starch gels (15\%) were prepared in $180 \mathrm{~mm} \times 180 \mathrm{~mm} \times 6 \mathrm{~mm}$ plastic moulds. Samples were applied to the gels on $5 \mathrm{~mm}$ squares of "Whatman No. 3" filter paper, and horizontal electrophoresis was conducted at $150 \mathrm{v}$ and room temperature with forced air cooling for $5 \mathrm{hr}$. This system was used for $\mathrm{LDH}$, $\mathrm{MDH}, \mathrm{IDH}, \mathrm{PGI}, 6-\mathrm{PGDH}$ and PGM resolution. All of these enzymes from redfishes were found to migrate anodally with the system.

The buffered staining mixture for the six enzymes was $100 \mathrm{mM}$ 'tris' and $10 \mathrm{mM} \mathrm{MgCl}$, with $100 \mathrm{mM}$ DL-lactate lithium salt (for LDH staining), or $50 \mathrm{mM}$ L-malic acid (for MDH staining), or $10 \mathrm{mM} \mathrm{6-}$ phosphogluconic acid, trisodium salt (for 6-PGDH staining), or $15 \mathrm{mM}$ DL-isocitric acid, trisodium salt and $100 \mathrm{mM}$ manganous sulphate (for IDH staining), or $10 \mathrm{mM}$ D-fructose-6-phosphate (for PGI staining), or $10 \mathrm{mM}$ glucose-1-phosphate, disodium salt (for PGM staining), and adjusted to $\mathrm{PH} 8.0$ with $\mathrm{HCl}$ or $\mathrm{NaOH}$, as required. Gel slices were stained for $\mathrm{LDH}$ and $\mathrm{MDH}$ by incubation in the dark in $100 \mathrm{ml}$ of the appropriate buffered staining mixture containing $30 \mathrm{mg}$ NAD, 30 $\mathrm{mg} \mathrm{MTT}$ and $5 \mathrm{mg}$ PMS. Gel slices were stained for 6-PGDH, IDH, PGI and PGM with a "Whatman No. 1" chromatography paper overlay containing $5 \mathrm{mg}$ NADP, $2 \mathrm{mg}$ MTT, $0.5 \mathrm{mg}$ PMS and (for PGI and PGM only) 10 units of glucose-6-phosphate dehydrogenase (Sigma Type XII) in $5 \mathrm{ml}$ of the appropriate substrate. SOD appeared as light spots against a darker blue background when any of these gels were exposed to strong light after specific staining.
An alternative buffer system (Ashton and Bradon, 1961) was used for typing esterase variants by polyacrylamide gel electrophoresis. Polyacrylamide gels (6.65\% acryalamide; $0.35 \% \mathrm{~N}, \mathrm{~N}$ '-methylene-bisacrylamide) were prepared in $180 \mathrm{~mm} \times 180 \mathrm{~mm} \times 6 \mathrm{~mm}$ plastic moulds with a buffer containing $1.4 \mathrm{~g} / \mathrm{l}$ citric acid, $5.58 \mathrm{~g} / \mathrm{l}$ 'tris', $1.18 \mathrm{~g} / \mathrm{l}$ boric acid, and $0.12 \mathrm{~g} / \mathrm{l}$ lithium hydroxide. The vessel buffer contained $11.8 \mathrm{~g} / \mathrm{l}$ boric acid and $1.2 \mathrm{~g} / \mathrm{l}$ lithium hydroxide. Electrophoresis was conducted at $250 \mathrm{v}$ until the "front" had migrated $100 \mathrm{~mm}$ past the sample origin. Gels were sliced horizontally and one section was stained for esterase with 1-naphthyl acetate and Fast Red TR salt (5 mg 1-naphthyl acetate dissolved in $5 \mathrm{ml}$ warm ethanol, diluted to $100 \mathrm{ml}$ with water, and mixed with another $100 \mathrm{ml}$ of water containing $50 \mathrm{mg}$ Fast Red TR salt). The other section was stained with the fluorogenic substrate $(10 \mathrm{mg}$ 4-methylumbelliferyl acetate dissolved in $2 \mathrm{ml}$ boiling ethanol, diluted to $100 \mathrm{ml}$ with $100 \mathrm{mM}$ acetate buffer $\mathrm{pH} 5.2$, and poured over the gel). Bands were visualized under long-wave ultraviolet illumination.

\section{Results and Discussion}

The enzymes, LDH, 6-PGDH and PGM, were found to be monomorphic for all specimens investigated and are consequently unimportant as systematic characters. The observed phenotype frequencies for polymorphic enzymes are listed in Table 1.

Cytoplasmic malate dehydrogenase (MDH; Lmalate:NAD oxidoreductase; EC 1.1.1.37) is determined in fishes and amphibians by two genes, Mdh-A

TABLE 1. Observed phenotype frequencies for common enzyme polymorphisms in redfishes (Sebastes sp.) off Newfoundland. (Frequencies in parentheses are those expected for genetic equilibrium.)

\begin{tabular}{lcrrrrrr}
\hline \hline Locus & Phenotype & \multicolumn{2}{c}{ S. marinus } & \multicolumn{2}{c}{ S. fasciatus } & \multicolumn{2}{c}{ S. mentella } \\
\hline Mdh-A & 1 & 25 & $(25.1)$ & 3 & $(0.8)$ & 36 & $(36.0)$ \\
& $1-2$ & 11 & $(10.7)$ & 6 & $(10.4)$ & 0 & \\
& 2 & 1 & $(1.1)$ & 35 & $(32.8)$ & 0 & \\
EsA & 1 & 26 & $(26.1)$ & 9 & $(10.8)$ & 34 & $(33.0)$ \\
& $1-2$ & 4 & $(3.7)$ & 22 & $(18.4)$ & 0 & $(1.9)$ \\
& 2 & 0 & $(0.1)$ & 6 & $(7.8)$ & 1 & $(0.03)$ \\
Idh & 1 & 30 & $(30.5)$ & 52 & $(51.6)$ & 5 & \\
& $1-2$ & 9 & $(8.0)$ & 10 & $(10.9)$ & 0 & \\
& 2 & 0 & $(0.5)$ & 1 & $(0.6)$ & 0 & \\
\multirow{4}{*}{ SOD } & $1-2$ & 0 & & 1 & $(0.6)$ & 0 & \\
& 2 & 35 & & 25 & $(23.7)$ & 4 & \\
& $2-3$ & 0 & & 11 & $(14.3)$ & 0 & \\
& 3 & 0 & & 4 & $(2.2)$ & 0 & \\
& 1 & 9 & $(5.8)$ & 9 & $(9.0)$ & 2 & $(2.3)$ \\
& $1-2$ & 8 & $(14.4)$ & 18 & $(18.0)$ & 2 & $(1.5)$ \\
& 2 & 12 & $(8.8)$ & 9 & $(9.0)$ & 0 & $(0.3)$ \\
\hline
\end{tabular}




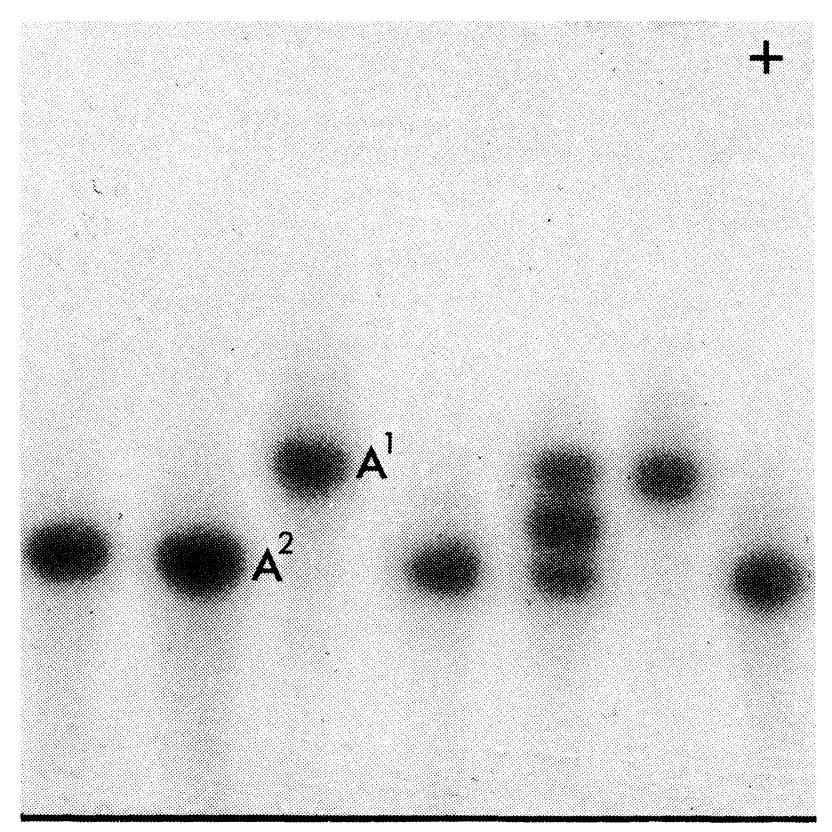

Fig. 1. Starch gel electrophorogram of liver extracts from redfish specimens stained to demonstrate malate dehydrogenase. Three phenotype patterns were observed: a single, anodallymigrating band which is interpreted as the product of a homozygous Mdh- $A^{\prime}$ genotype; a single, less-anodal band, genotype $\mathrm{Mdh}-\mathrm{A}^{2}$; and a 3-banded pattern (MDH-A' homodimer, $\mathrm{MDH}-\mathrm{A}^{1} / \mathrm{MDH}-\mathrm{A}^{2}$ heterodimer, $\mathrm{MDH}-\mathrm{A}^{2}$ homodimer) in specimens that are $M d h-A^{1} / M d h-A^{2}$ heterozygotes.

and Mdh-B (Bailey et al., 1970). The degree of transcription varies with the tissue type, MDH-A being the dominant isozyme in liver and $\mathrm{MDH}-\mathrm{B}$ in skeletal muscle. The Mdh-A locus of North Atlantic redfishes was found to be polymorphic with two alleles, designated Mdh- $A^{1}$ and $M d h-A^{2}$, determining the three liver $M D H-$ A phenotypes: $M D H-A^{1}, M D H-A^{1} / M^{2} H_{-} A^{2}$, and $\mathrm{MDH}-\mathrm{A}^{2}$ (Fig. 1). There is a marked difference in the frequencies of the two Mdh-A alleles between S. marinus and $S$. fasciatus, the estimated gene frequencies ( \pm standard deviation) of Mdh- $\mathrm{A}^{1}$ being $0.82 \pm 0.04$ and $0.14 \pm 0.04$ respectively.

Electrophoresis of liver homogenates revealed two classes of polymorphic esterases: EsA which hydrolyzes 1-naphthyl acetate, and EsB which hydrolyzes 4-methylumbelliferyl acetate. The EsA polymorphism (Fig. 2) also demonstrated biochemical genetic differences between $S$. marinus and $S$. fasciatus, the frequency of $E s A^{1}$ being $0.93 \pm 0.03$ in $S$. marinus and $0.54 \pm 0.06$ in $S$. fasciatus. The frequency of $\mathrm{EsB}^{1}$ was very similar for both species, being $0.45 \pm 0.07$ in $S$. marinus and $0.50 \pm 0.06$ in $S$. fasciatus.

SOD-typing also demonstrated that $S$. marinus and $S$. fasciatus in southern Newfoundland waters behave as biological species. Although most specimens of either species exhibited the SOD ${ }^{2}$ phenotype,

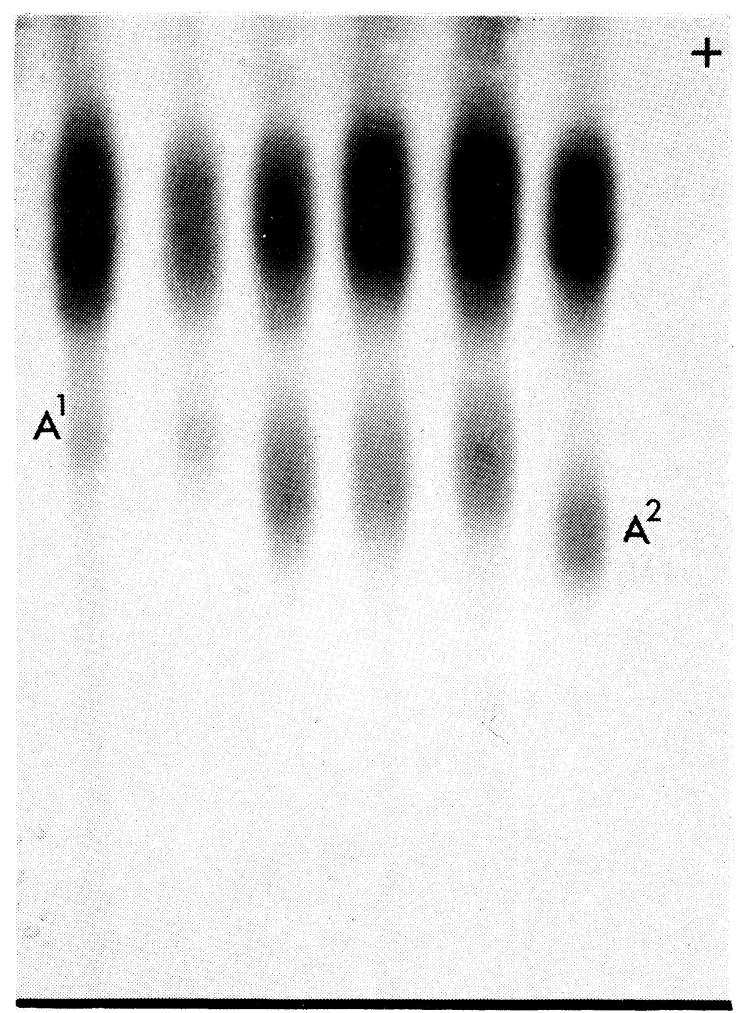

Fig. 2. Polyacrylamide gel electrophorogram of liver extracts from redfish stained to reveal general anodal esterase activity. There is a strongly-staining invariant region and a lessintense polymorphic region (EsA) in which one may observe either a single, fast-migrating band (EsA $\left.{ }^{1}\right)$, or a single, slower-migrating band $\left(E S A^{2}\right)$, or a broad, multicomponent band which overlaps EsA ${ }^{1}$ and $\operatorname{EsA}^{2}$ (genotype EsA ${ }^{1} / E_{s} A^{2}$ ).

tri-allelic polymorphism involving $S O D^{1}, S O D^{2}$ and SOD $^{3}$ was evident. Variant phenotypes $(n=16)$ were only found among specimens previously identified as $S$. fasciatus on the basis of gasbladder musculature.

The IDH polymorphism is of little uitility as a biochemical discriminator, because the three phenotypes occur at about the same frequency in $S$. marinus and $S$. fasciatus.

The specimens of S. mentella, obtained from the commercial catch off Labrador were not in sufficiently good condition to permit analysis of IDH, SOD or EsB. However, it was quite clear from MDH-A and EsA typing that $S$. mentella and $S$. fasciatus are valid species. The frequency of $\mathrm{Mdh}-\mathrm{A}^{2}$ was $0.86 \pm 0.06$ in beaked redfish specimens classified as $S$. fasciatus on the basis of gasbladder musculature, but this allele was absent in specimens classified morphologically as $S$. mentella. $\mathrm{Es}^{2}{ }^{2}$ was common in S. fasciatus $(\mathrm{q}=0.46 \pm$ $0.06)$ but rare in $S$. marinus ( $q=0.07 \pm 0.03$ ) and absent in S. mentella. The observations indicate that $S$. mentella may be more closely related to $S$. marinus than to $S$. fasciatus, because Mdh- $A^{1}$ was the most common 
allele found in $S$. marinus and $S$. mentella, whereas $M d h-A^{2}$ was more common in $S$. fasciatus. Similarly, EsA ${ }^{2}$ was common in $S$. fasciatus but rare in $S$. marinus and probably absent in $S$. mentella. Despite this similarity between $S$. mentella and $S$. marinus, the Mdh- $A^{1}$ allele frequencies ( 1.00 and 0.82 respectively) are sufficiently different $(P<0.001)$ to confirm that they are genetically distinct populations.

The significance of these findings to redfish fisheries biology is the biochemical genetic confirmation that the category of "beaked" redfish used in current stock assessments is biologically heterogeneous, and its use is likely to result in management decisions that are invalid. As demonstrated by the preliminary observations reported above, it should soon be possible to devise a biochemical genetic protocol that will discriminate readily between individuals of the sibling species of Sebastes in the Northwest Atlantic and so permit a more rational utilization of the resource.

\section{References}

ASHTON, G. C., and A. W. H. BRADON. 1961. Serum $\beta$-globulin polymorphism in mice. Aust. J. Biol. Sci., 14: 248-253.

AYALA, F. J., J. R. POWELL, M. L. TRACEY, C. A. MOURAO, and S. PEREZ-SALAS. 1972. Enzyme variability in the Drosophila willistoni group. IV. Genic variation in natural populations of Drosophila willistoni. Genetics, 70: 113- 139.
BAILEY, G. S., A. C. WILSON, J. E. HALVER, and C. L. JOHNSON 1970. Multiple forms of supernatant malate dehydrogenase in salmonid fishes. J. Biol. Chem., 245: 5927-5940.

BARSUKOV, V. V. 1968. The systematic relationship of redfishes of the genus Sebastes of the Northwest Atlantic Ocean. Doklady Akad. Nauk. SSSR, 183: 479-482. (Transl. from Russian in Dokl. Biol. Sci. 183: 734-747.)

1972. Systematics of the Atlantic redfishes. Trudy, PINRO, 28 128-142. (Fish. Res. Board Canada Transl. Ser., No. 2531.)

BARSUKOV, V. V., and G. P. ZAKHAROV. 1972. Morphological and biological characteristics of the American redfish. Trudy, PINRO, 28: 143-173. (Fish. Res. Board Canada Transl. Ser., No. 2488.)

LITVINENKO, N. N. 1974. Coloration and other morphological characters distinguishing juvenile Sebastes fasciatus from juvenile $S$. mentella (Scorpaenidae). J. Ichthyol., 14: 591-595.

1980. The structure, function, and origin of the drumming muscles in the north Atlantic ocean perches of the genus Sebastes (Scorpaenidae). J. Ichthyol., 20: 89-98.

NAFO. 1981. Report of Scientific Council, Regular Meeting, June 1981: redfish speciation and stock delineation. NAFO Sci. Coun. Rep., 1981: 50-51.

NI, I-H. 1981a. Separation of sharp-beaked redfishes, Sebastes fasciatus and S. mentella, from northeastern Grand Bank, by morphology of extrinsic gasbladder musculature. J. Northw. Atl. Fish Sci. 2: $7-12$.

1981b. Numerical classification of sharp-beaked redfishes, Sebastes mentella and S. fasciatus, from northeastern Grand Bank. Can. J. Fish. Aquat. Sci., 38: 873-879.

POWER, D. and I-H. NI. 1982. Morphology of the extrinsic gasbladder musculature in the golden redfish, Sebastes marinus. J. Northw. Atl. Fish. Sci., this volume, p. 165-168.

TEMPLEMAN, W. 1980. Incidence of subcaudal melanophores in preextrusion larvae of redfish species in the Newfoundland and Labrador area. J. Northw. Atl. Fish. Sci., 1: 7-19.

TEMPLEMAN, W. and E. J. SANDEMAN. 1957. Two varieties of redfish in the Newfoundland area. Fish Res. Bd. Canada, Atlant. Prog. Rep., No. 66: 20-23. 